\title{
Solar control of ambient ionization of the ionosphere near the crest of the equatorial anomaly in the Indian zone
}

\author{
S. K. Chakraborty and R. Hajra \\ Department of Physics, Raja Peary Mohan College, Uttarpara, Hooghly, Pin.712258, India \\ Received: 11 May 2007 - Revised: 23 November 2007 - Accepted: 4 December 2007 - Published: 4 February 2008
}

\begin{abstract}
Long-term (1978-1990) total electron content (TEC) data have been analyzed to show the dependence of ambient ionization on EUV radiation from the Sun. TEC observations were made at Calcutta $\left(22.58^{\circ} \mathrm{N}, 88.38^{\circ} \mathrm{E}\right.$ geographic, dip: $32^{\circ} \mathrm{N}$ ), situated virtually below the northern crest of the equatorial ionization anomaly. Day-to-day changes in TEC at different local times do not show any significant correlation with F10.7 solar flux. A good correlation is, however, observed between the F10.7 solar flux and the monthly mean TEC when both are considered on a long-term basis, i.e. either in the ascending (1986-1990) or in the descending (1979-1985) phase. In the early morning hours the correlation coefficient maximizes around the 08:00-10:00 $\mathrm{h}$ IST interval. The flux independent nature of diurnal TEC is evident around the noon time hours of only a few months in the descending phase for F10.7 values greater than 150 unit. Variation of TEC for the whole time period (1979-1990) also exhibits a prominent hysteresis effect. The remarkable feature of the hysteresis effect is its local time dependence, leading to a temporal flip-over. Solar flux-normalized TEC values show a clear seasonal dependence with asymmetrical variations in the two equinoxes. The amplitudes of the equinoctial peaks reveal a prominent local time dependence. A further normalization leads to a typical local time variation of TEC. Based on solar flux, seasonal and local time dependent features of TEC, an empirical formula has been developed to represent the TEC variation in the early morning hours. It yields a quantitative estimate of the solar flux dependent nature of the TEC variation. The formula has been validated using the available TEC data and data from the neural network.
\end{abstract}

Keywords. Ionosphere (Equatorial ionosphere; Modeling and forecasting; Solar radiation and cosmic ray effects)

Correspondence to: S. K. Chakraborty

(skchak2003@yahoo.com)

\section{Introduction}

Two most prominent features of the equatorial ionosphere are: (i) the equatorial ionization anomaly and (ii) the intense form of the irregularities. During daytime the ionization distribution in the ionosphere of the low-latitude region is modified by the fountain effect (Hanson and Moffett, 1966). The electrodynamic $E x B$ drift produces a trough of ionization at the equator with two crests around $15^{\circ}-20^{\circ}$ geomagnetic latitudes - known as the equatorial ionization anomaly. The neutral wind further introduces asymmetries in the anomalous distribution of the ionization with larger plasma flow (towards the hemisphere of the stronger poleward wind) and a stronger anomaly crest occurring in the opposite hemispheres (Balan and Bailey, 1995). The latitudes of the anomaly crests and the strength of the anomaly are found to vary with day, month, season, solar activity, as well as longitudes (Rush and Richmond, 1973; Huang et al., 1989). The world's largest value of total electron content (TEC) is observed around the equatorial anomaly crest. For the same percentage variation of ionization the largest deviation in TEC is recorded around this region. With the development of the equatorial anomaly, the movement of the crest across a fixed point of observation may be reflected in the measured values of TEC at the point under varying geophysical conditions. For any study concerning the temporal variability of the equatorial ionization a location near the crest would be most suitable. The paper presents the results of analysis of long-term (1978-1990) TEC data obtained from Calcutta $\left(22.58^{\circ} \mathrm{N}, 88.38^{\circ} \mathrm{E}\right.$ geographic, dip: $32^{\circ} \mathrm{N}$ ), using the geostationary satellite ETS-2. The station has a peculiar location with respect to the equatorial anomaly crest (Fig. 1). During the high solar activity period, as the crest of the anomaly shifts to higher latitudes, the station is within the anomaly belt. But during the low solar activity epoch the crest shifts towards low latitudes and the station is situated just below the northern crest. Hence, TEC around this location is very sensitive to the variation

Published by Copernicus Publications on behalf of the European Geosciences Union. 


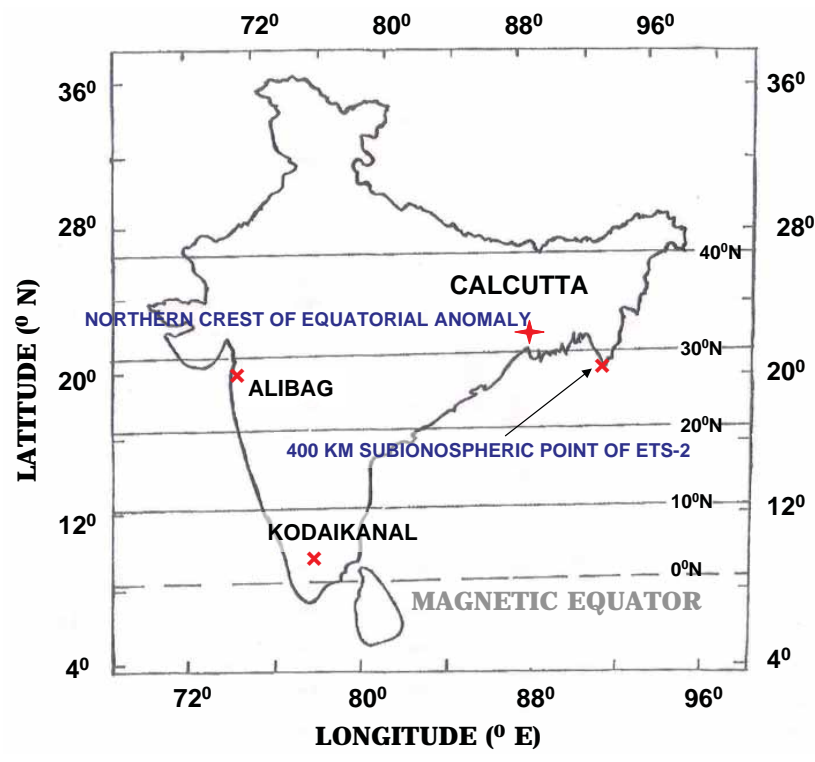

Fig. 1. Location of the observing station Calcutta, with respect to the equatorial anomaly crest of the Indian longitude sector. Geographic latitudes and longitudes are shown. Horizontal lines indicate isodip lines (geographic). Location of the 400-km subionospheric point of the satellite (ETS-2) path is also shown.

of solar activity, as dictated by solar fluxes. In addition to solar flux, neutral wind, tides and waves, and geomagnetic activity affect the TEC values at a location. There is a complex interplay among various geophysical phenomena, such as solar activity, equatorial fountain, geomagnetic activities, neutral wind, tides and waves, etc., which control the ambient ionization around the equatorial anomaly region. TEC at a location is actually the integrated effect of production, loss and transport processes. Production is mainly controlled by solar radiation while transport is dominated by the equatorial fountain effect.

In the present paper attempts have been made to identify the solar activity dependent features of the ionization variation considering a long-term (1978-1990) database of TEC and a $10.7 \mathrm{~cm}$ solar flux. The peculiarity of the database is that it contains both the descending (1979-1985) and ascending (1986-1990) phases of the solar cycles. The solar activity dependent features have been discussed in various papers (Golton and Walker, 1971; Rastogi and Sharma, 1971; Huang et al., 1989; Klobuchar et al., 1991; Prasad and Rama Rao, 1993; Feichter and Leitinger, 1997; Gupta and Singh, 2001; Jayachandran et al., 2004; Wu et al., 2004). These are mostly based on data for one solar cycle or less, or observations were made from mid/higher latitude regions. On the contrary, the present investigation using a long-term database of TEC involving both the phases of solar cycles around the region of the equatorial anomaly crest of the Indian zone is reported for the first time.
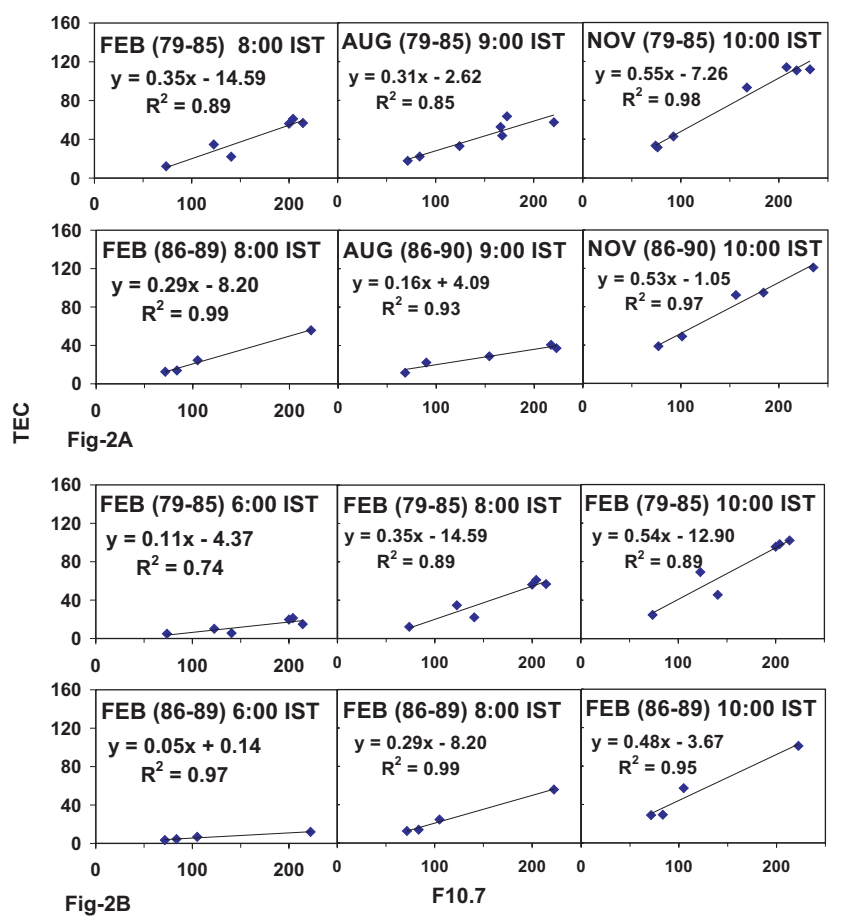

Fig. 2. (A) Monthly mean TEC vs. 10.7-cm solar flux plots for descending (1979-1985) and ascending (1986-1990) phases of solar cycles at different months and at different local times [IST(h)= $\mathrm{UT}+530 \mathrm{~h}]$. Satellite transmission was off during February 1981 and 1990. 1 TEC unit $=10^{16}$ electrons $/ \mathrm{m}^{2}$. Equations of linear fit and corresponding $\mathrm{R}^{2}$ values are shown. (B) For the month of February, monthly mean TEC and F10.7 solar flux plots for the descending and ascending phases of the solar cycle at different local times (IST (h)).

\section{Data}

Ionospheric total electron content data obtained by the Faraday rotation technique of a VHF $(136.11 \mathrm{MHz})$ signal from a geostationary satellite ETS-2 $\left(130^{\circ} \mathrm{E}\right)$ have been analyzed for the present investigation. The observations were made at Calcutta $\left(22.58^{\circ} \mathrm{N}, 88.38^{\circ} \mathrm{E}\right.$ geographic, dip: $\left.32^{\circ} \mathrm{N}\right)$ with a $400-\mathrm{km}$ subionospheric point located at $21^{\circ} \mathrm{N}, 92.7^{\circ} \mathrm{E}$, dip: $27^{\circ} \mathrm{N}$ geographic (Fig. 1). Due to unavailability of a proper database of solar EUV radiation, 10.7-cm solar flux (F10.7) is considered as a surrogate index. The solar flux data have been downloaded from the Internet.

\section{Results and discussion}

Production of ionization is mainly controlled by the solar radiation in the EUV range. Variation in the solar EUV radiation is expected to cause changes in the ionospheric temperature, dynamics and composition. In the absence of a proper database of EUV radiation, 10.7-cm solar flux may be considered as a surrogate index of solar activity (Kane, 2005; 
Mahajan and Dwivedi, 2005). In the present investigation attempts have been made to identify the contribution of a production term, as dictated by solar flux, in developing the ionization profile. The whole data period has been categorized in the ascending (1986-1990) and descending (1979-1985) phases of the solar cycle and the monthly mean values of TEC have been calculated ( 1 TEC unit $=10^{16}$ electrons $/ \mathrm{m}^{2}$ ). To observe the solar flux dependent nature, monthly mean TEC values are considered in conjunction with F10.7 solar fluxes. Figure 2a presents typical solar flux vs. monthly mean TEC plots at different local times pertaining the solar activity increasing and decreasing phases. A good correlation between F10.7 solar flux and TEC is evident in the plots. A correlation is found to be somewhat larger in the ascending epoch compared to that in the descending phase. Moreover, variations of ambient ionization in the equinoctial and the December solstitial months are found to be more sensitive to solar flux changes. A higher " $m$ " value in the linear fit and/or a higher value of the correlation coefficient indicates this sensitivity. The rate of increase depends primarily on the rate of production of the ionization. Photoionization of oxygen produces the ionization; molecular $\mathrm{N}_{2}$ does not contribute much. The change in the ratio of these gasses $\left([\mathrm{O}] / \mathrm{N}_{2}\right)$ can alter the production rate and a high value of the ratio may account for the winter anomaly. Titheridge (1974), using TEC data from Honolulu $\left(20^{\circ} \mathrm{N}\right)$, obtained an annual variation in the production rate change and suggested that the changes in $[\mathrm{O}] / \mathrm{N}_{2}$ ratio may be responsible for the observed production rate change in December. The seasonal changes in ionization might be associated with the seasonal anomaly in the F2 layer electron density (Millward et al., 1996), as well as the change in composition of the ionosphere. The anomalous effect in winter may also be due to energetic photo electrons from the summer hemisphere of conjugate points (King et al., 1968). The test of significance of the observed correlation coefficients indicates a high level of significance except for a few [May (1979-1983, 08:00 IST) at a 1\% level of significance, February (1979-1985, 06:00 IST) at a 1\% level of significance, February (1986-1990, 06:00 IST) at a 0.5\% level of significance and February (1986-1990, 10:00 IST) at a $1 \%$ level of significance] which can be rejected at very low significance levels.

For a particular month February, Fig. 2b shows the variation of TEC with F10.7 solar flux at different local times of the morning sector. It exhibits the local time dependent effects of solar flux variation. The correlation coefficient maximizes around the time interval of 08:00-09:00 $\mathrm{h}$ IST, and no saturation effect is detected in the monthly mean TEC variation. The feature is the same in all months and phases of the solar cycles.

In the ascending/descending phase of the solar cycle, when daily values of TEC are considered in association with F10.7 solar flux, a good linear fit is observed. Diurnal TEC values at different local times are plotted in Fig. 3a considering both the phases of the solar cycles. The dates with
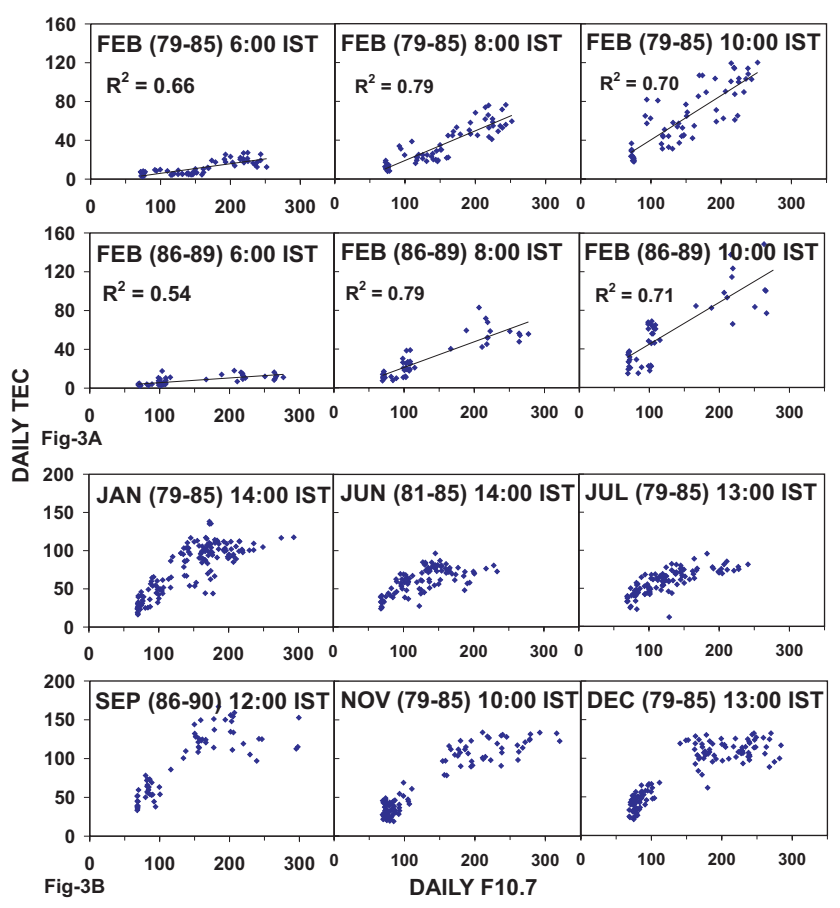

Fig. 3. (A) Diurnal TEC values vs. daily $10.7-\mathrm{cm}$ solar fluxes for the quiet days at different local times (IST (h)) for the month of February of descending and ascending phases. From the year 1980 onwards of the descending phase the satellite transmission was off for a few days in February due to eclipsing - limiting the total number of data points. (B) Plots of quiet day TEC values for various months vs. daily F10.7 solar fluxes at the prescribed local times (IST (h)) showing saturation effect.

$D_{s t}<-50 \mathrm{nT}$ are discarded on the assumption of disturbed days (Akasofu, 1981). Obviously solar flux response maximizes around 08:00-09:00 $\mathrm{h}$ IST of the descending phase. In the ascending phase, the correlation coefficient attains maximum values at two time intervals, one around 08:0009:00 $\mathrm{h}$ IST, another around 12:00-13:00 $\mathrm{h}$ IST. As production is mainly dictated by solar fluxes, early morning maxima may represent the dominant role played by the solar radiation in modulating the TEC profile around the sunrise sector.

Solar flux dependent features of diurnal maximum and minimum values of TEC are depicted in Fig. 4. Diurnal TEC minimum mainly occurs around 04:00-05:00 h IST. It shows little correlation with daily solar flux. The period corresponds to no direct solar control of ionization. On the contrary, maximum values of diurnal TEC are generally observed around 11:00-14:00 h IST. When solar flux related variations of diurnal maxima are studied, the following features emerge:

(i) good correlation with daily solar flux, greater in the ascending phase than in the descending phase,

(ii) high level of significance of correlation coefficients, 


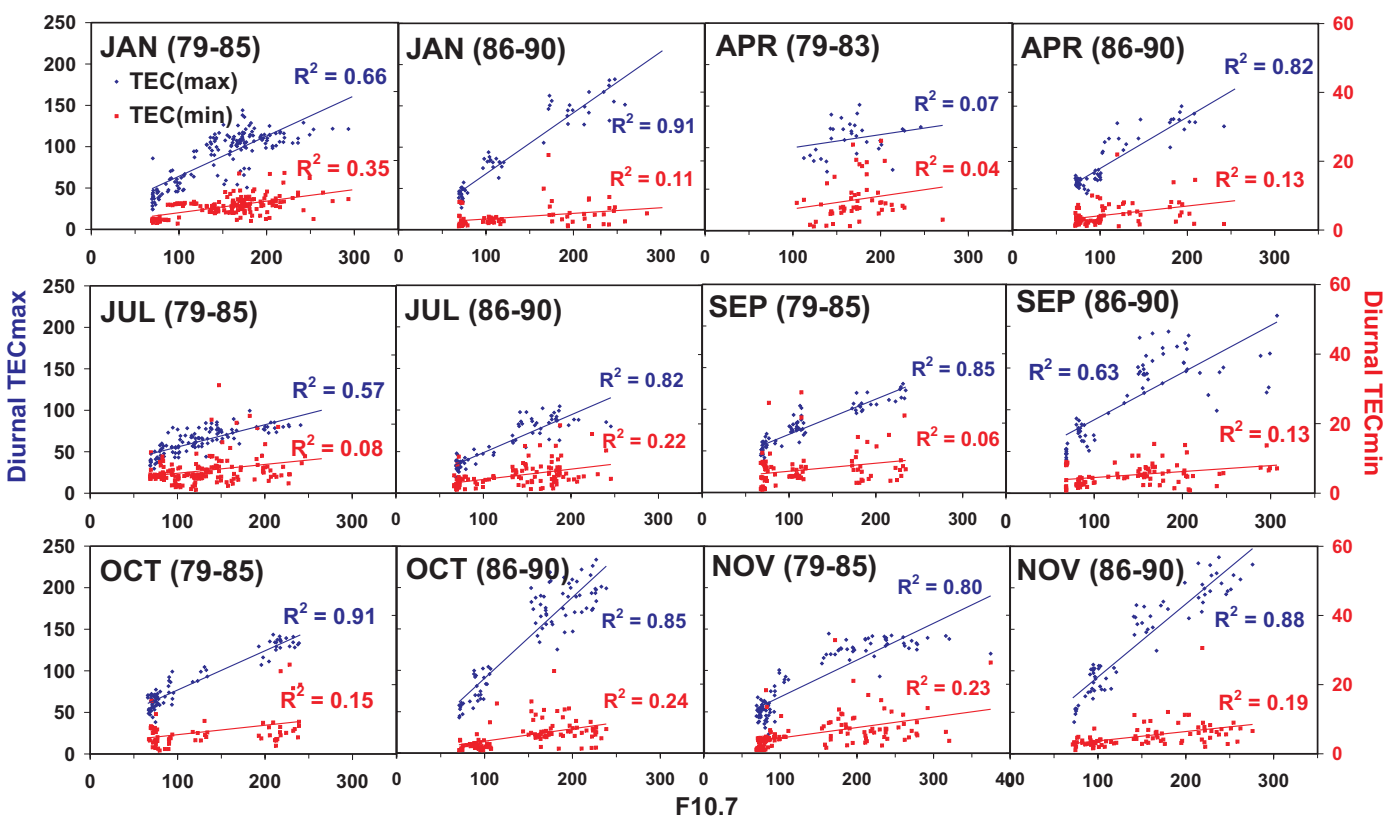

Fig. 4. Variation of daily maximum and minimum values of TEC with daily solar flux (F10.7).

(iii) only in few months of the descending phase an apparent saturation-like effect for the solar flux greater than 150 units,

(iv) lower correlation compared to the early morning hours except for a few months (June, July, August, October) of the ascending phase (1986-1990).

Diurnal maxima are assumed to be the combined effect of production and transport terms in the continuity equation. The effect of production maximizes around 08:0010:00 $\mathrm{h} \mathrm{ST}$, and contribution of the transport term becomes dominant thereafter, with the solar flux effect remaining more or less constant (Garriot and Smith, 1965; Iyer and Rastogi, 1978; Raghava Reddi et al., 1982). The transport of ionization is mainly controlled by the equatorial fountain effect. The electrodynamic ExB drift at the magnetic equator and subsequent diffusion generates the plasma fountain and anomaly (Hanson and Moffett, 1966). The neutral wind makes the fountain and anomaly asymmetric (Balan and Bailey, 1995). An estimate of the equatorial electric field responsible for the fountain effect may be obtained from the electrojet strength. To extract the quantitative contribution of the transport mechanism, further investigation based on electrojet data is essential (Rastogi and Rajaram, 1971; Rush and Richmond, 1973; Sethia et al., 1980; Gupta and Singh, 2001).

Sometimes the saturation-like effect is observed in the noon time diurnal TEC variation, as shown in Fig. 3b. The feature is primarily observed in the solstitial months of the descending phase, not in the ascending phase except in the months of September and December. Further, the flux in- dependent nature is absent in the other time periods of the diurnal TEC variation. Most of the workers (Balan et al., 1993; Gupta and Sing, 2001) obtained a linear relationship between the TECmax and the F10.7 for solar flux values up to about 200 flux units. Gupta and Singh (2001), considering TEC data from Delhi for the rising phases of the 21st and 22nd solar cycles, found the saturation effect at different seasons with a nonlinear fit. Present observations support the saturation-like effect only for a few months of the descending phase - this may be due to the peculiar position of the observing station relative to the equatorial anomaly crest. The same effect at larger values of F10.7 for all latitudes from $17^{\circ} \mathrm{N}$ to $47^{\circ} \mathrm{N}$ and in all seasons was reported by Balan et al. (1993) using TEC data for the period (19801985). The saturation effect may be due to an inherent deficiency of F10.7 to represent the variation of EUV, for a $2800-\mathrm{MHz}$ radio flux exceeding 200 units. Although it was reported by Kane (2005) that the saturation effect between F10.7 and EUV is not an invariable feature, it may occur in some months when F10.7 exceeds 200 units but not in all such months. The time interval of the occurrence of the saturation-like effect in TEC is such that not only production, for which solar flux is mainly responsible, but transport of ionization is also important. The equatorial fountain and the thermospheric neutral winds mainly control the transport processes. The daytime average vertical ExB plasma drifts at the magnetic equator do not vary considerably with solar activity, but the day-to-day variability of the vertical drifts, which becomes maximum at equinox, decreases systematically with increasing solar flux (Fejer and Scherliess, 2001). Again, for the wind system, the meridional neutral wind is 

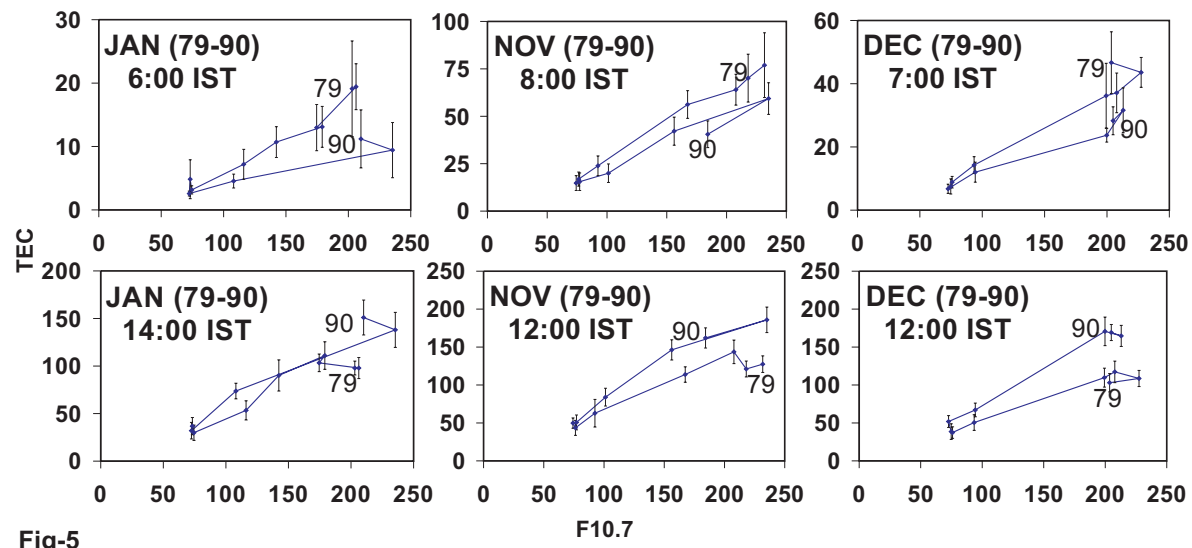

Fig-5

Fig. 5. Monthly mean TEC vs. monthly mean solar flux for the period (1979-1990) at different local times (IST (h)) showing prominent hysteresis phenomenon. The vertical bars indicate standard deviation in TEC values.
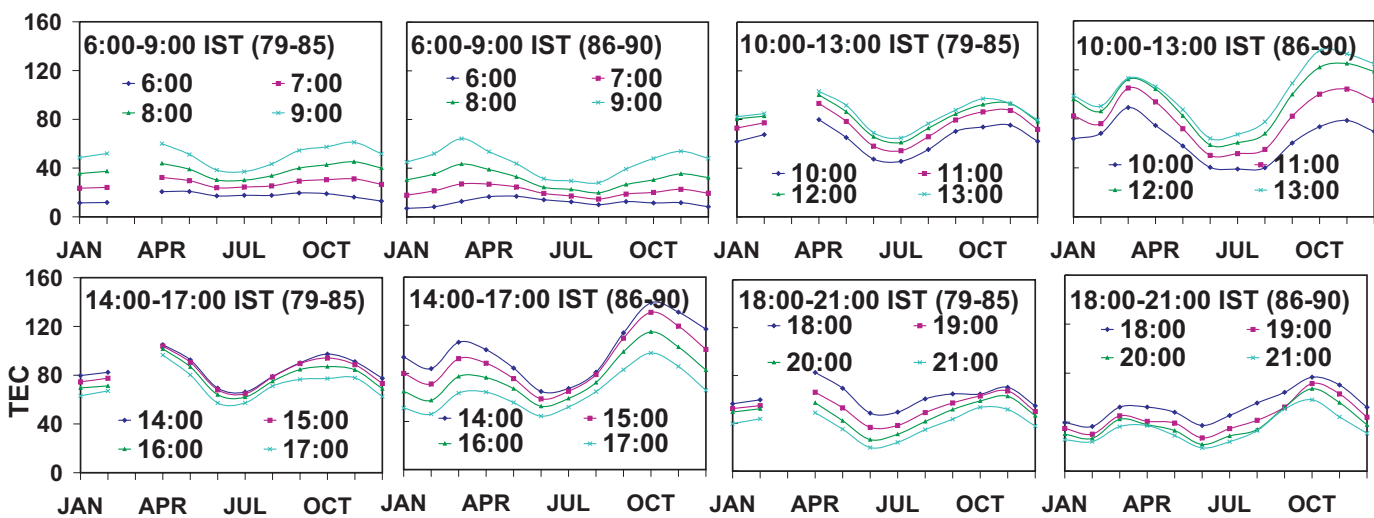

JAN APR JUL OCT
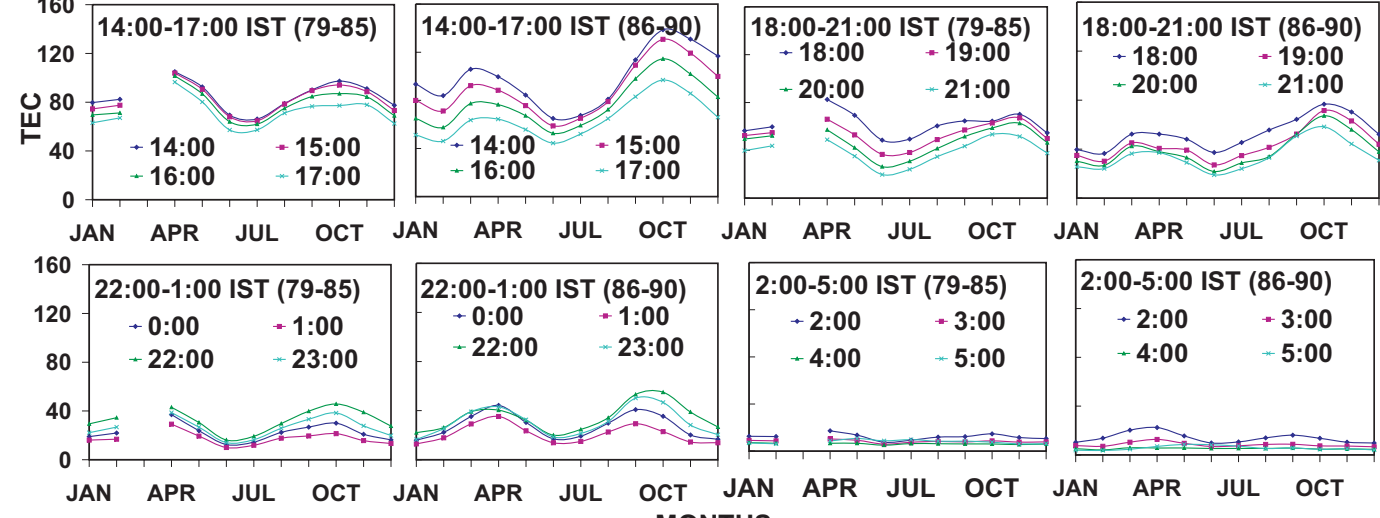

JAN APR JUL OCT

MONTHS

Fig. 6. Seasonal plots of solar flux normalized TEC values at different local times (IST (h)). As satellite transmission was off due to satellite eclipse, TEC data for the month of March in the descending phase (1979-1985) are unavailable.

always poleward throughout the day during the high solar activity period. The diurnal amplitudes of the wind decrease with increasing solar activity and vice versa (Igi et al., 1999). Emmert et al. (2006) reported that the dependence of the neutral wind on the F10.7 solar flux either weakens or saturates around $\mathrm{F} 10.7=150$ at most latitudes and local times. As TEC is an integrated parameter of production, loss and transport processes, the above-mentioned effects may be reflected in the TEC variation.

Although a good correlation with a high level of significance is observed when TEC (both diurnal and monthly mean) is considered on a long-term basis, i.e. either for the descending (1979-1985) or ascending (1986-1990) phase, the day-to-day changes in TEC do not show any significant correlation with the day-to-day changes in solar flux. The absence of any short term relation suggests that TEC around the location is not a simple function of solar flux alone; deviations may be attributed to the changes in temperature, composition and dynamics (Doherty et al., 2000) of the ionosphere. 


\section{Hysteresis effect}

One important feature of long-term variation of TEC with solar flux is the hysteresis effect. When monthly mean TEC values are plotted against mean solar flux, TEC variations in the ascending phase follow a path different from that of the descending epoch, similar to the hysteresis effect shown by the ferromagnetic material. A prominent hysteresis effect is evident in the plots of Fig. 5. The vertical bars represent the corresponding standard deviations. The effect is observed in all months and at all local times of the whole data period (1979-1990), though some data fall within the $1-\sigma$ level. The effect is more prominent in the high solar activity period than in the lower one. The hysteresis may be classified as positive or negative according as TEC in the descending part of solar cycle lies above or below that of the ascending part. In most cases positive hysteresis effect is observed during the time interval of 06:00-09:00 h IST, with higher values of TEC in the 1979-1980 periods than the corresponding values in the 1989-1990 periods. One remarkable feature of the hysteresis phenomenon is its local time dependence. For more or less the same solar flux the TEC variation shows a positive, as well as a negative effect at different local times. In the pre-noon to noon time hours (11:0014:00 $\mathrm{h}$ IST) TEC in the ascending phase lies above that of the descending epoch, contrary to the early morning feature. This implies negative hysteresis and the change-over takes place around 11:00-13:00 h IST at various months. The effect becomes again positive in the afternoon to early evening hours (17:00-19:00 $\mathrm{h}$ IST). Thus, the variation of TEC with solar flux exhibits not only hysteresis, but an intricate local time effect is also prominent. The reversal occurs earlier (09:00-11:00 h IST), mostly in the equinoctial and December solstitial months, while for the rest of the months the flipover takes place at a later time interval (12:00-13:00 h IST). Although the phase reversal occurs twice a day in the December solstitial months, for the rest of the months the same is repeated four times. Two extra reversals occur at around 20:00-00:00 $\mathrm{h}$ IST and 01:00-04:00 $\mathrm{h}$ IST, respectively. The ETS-2 beacon signal was off during the satellite eclipse period of the years 1980-1985, so data were not complete for March, September and October (1980, 1981, 1982), April (1980, 1984, 1985).

The hysteresis effect observed with TEC is similar to that observed in foF2, the semi-thickness of the F2 layer, the slab thickness and M(3000)F2 with sunspot number (Huang,1963; Rao and Rao, 1969; Huang and Bor-Shenn, 1976; Smith and King, 1981; Apostolv and Alberca, 1995). The geomagnetic activity lags the sunspot activity by about two years, and the magnetic activity in the falling part of the solar cycle is larger than that in the rising part. The hysteresis effect in foF2 was reported to be the result of the cumulative influences of magnetic disturbances (Rao and Rao, 1969; Apostolv and Alberca, 1995; Mikhailov and Marin, 2001). Various other causes of hysteresis, as suggested by several workers, may be mentioned as:

(i) larger solar radiation in the falling part of the solar cycle than in the rising part (Huang, 1963),

(ii) the delayed response of the sunspot number (Huang and Bor-Shenn, 1976),

(iii) changes in the ion composition lag six months behind the changes in solar flux (Titheridge, 1974),

(iv) uncertainty in the definition of the sunspot number in terms of the sunspot group and individual spot (Davies, 1989),

(v) the inherent hysteresis effect detected in the variation of solar EUV radiation with a $10.7-\mathrm{cm}$ solar flux (Kane, 2005).

The positive hysteresis effect observed in the present investigation may support the idea of the cumulative effects of geomagnetic disturbances occurring in the falling part of the solar cycle. Dates with $D_{s t}$ values less than $-50 \mathrm{nT}$ may be related to disturbed days. In the descending part of the $21 \mathrm{st}$ solar cycle the total number of such disturbed days is $403 / 347$ (1980-1985/1981-1985), while in the ascending phase of the 22nd solar cycle (1986-1990) the same is 278 - the ascending phase registered less, though the two phases correspond to the different cycles. The cumulative effects of the magnetic disturbances may produce changes in neutral composition, temperature and thermospheric wind pattern and these may modulate the trend of the diurnal variation. The positive hysteresis effect may also be due to the inherent deficiency of the F10.7 solar flux to represent EUV radiation for higher solar flux values.

The negative hysteresis effect or the peculiar local time dependence of hysteresis deserves further investigation. TEC measurements contain a large contribution from above the peak of the ionosphere, so they will be sensitive to interhemisphere flow (Titheridge and Buonsantu, 1983). The equatorial vertical drift and corresponding fountain effect may modulate diurnal variability of TEC, and the fountain effect is reported not to be directly related to solar flux (Doherty et al., 2000). Further, changes in the neutral wind may give rise to fluctuations in the zonal electric field. This may cause changes in the strength of the anomaly. Movement of the peaks of the equatorial anomaly may lead to rapidly increasing TEC in the equatorial zone, although its intricate dependence on solar epochs has yet to be explored. The meridional wind effect is also efficient at lower latitudes (Mikhailov and Marin, 2001). Moreover, the solar ionizing radiation changes with solar facular area. The time variation of the faculae-associated radiation for a fixed sunspot number may affect the production of the ionization in the $\mathrm{E}$ and F layers (Smith and King, 1981). For better realization of phase reversal, values of the solar parameters, the long-term 
temporal effects of anomaly parameters and also of the wind system are to be taken into account.

The geomagnetic activity operates more effectively during the night than during the day (Huang and Bor-Shenn, 1976). Depending on the latitude, the local time of the observing station with respect to the initiation of the storm, the ionosphere may have a variable relaxation time for geomagnetic disturbances. The cumulative effect of the enhanced equatorward thermospheric wind resulting from the auroral heating may contribute to the NmF2/TEC increases. Though the idea supports the positive hysteresis at night, its phase reversal requires intensive study.

\section{Seasonal variability of TEC}

When TEC is normalized with respect to the F10.7 solar flux, and seasonal variation is considered, an asymmetrical double-peak response results. Typical plots of solar flux normalized TEC values for various months at different local times are shown in Fig. 6. The important features of this semiannual variation are the peculiar local time dependence of the asymmetrical peak amplitudes and its temporal flipover (Fig. 7). During the time interval 07:00-12:00 h IST of the ascending phase (1986-1990), amplitudes of vernal equinoctial peaks are found to be larger compared to the autumnal equinoctial peaks. From 13:00 h IST onwards autumnal equinoctial peak amplitudes are observed to exhibit greater values and the trend continues up to 23:00 $\mathrm{h}$ IST. Vernal equinoctial peak amplitudes again assume larger values up to $03: 00 \mathrm{~h}$ IST, with a gradual decay of the peak magnitudes. The double-peak nature ceases to exist during 04:0005:00 $\mathrm{h}$ IST of the ascending phase.

A similar semiannual asymmetrical double-peak response is also detected in the descending epoch (1979-1985) of the 21 st solar cycle. But contrary to the observed features in the ascending phase larger vernal equinoctial peak amplitudes persist throughout the day, up to 19:00 $\mathrm{h}$ IST. Thereafter, autumnal equinoctial peaks assume greater values for two to three hours and finally, the initial trend is recovered with a gradual decay of the autumnal peak amplitudes around the pre-dawn hours (03:00-05:00 h IST). It may be mentioned that for the month of March in the descending phase (19791985) there is a data gap due to a satellite eclipse. In both the phases the semiannual variation registered minima at the summer solstitial months (June, July), with winter solstitial months (November, December, January) exhibiting higher values (winter anomaly). Thus, both phases exhibit a seasonal/winter anomaly, as well as an equinoctial asymmetry.

The seasonal anomaly is explained in terms of the yearly variation of the thermospheric composition. In the F2 layer ion production is related to the concentration of atomic oxygen, and the loss of ions depends on the molecular gasses $\left(\mathrm{N}_{2}, \mathrm{O}_{2}\right)$. A higher atomic-to-molecular ratio in winter

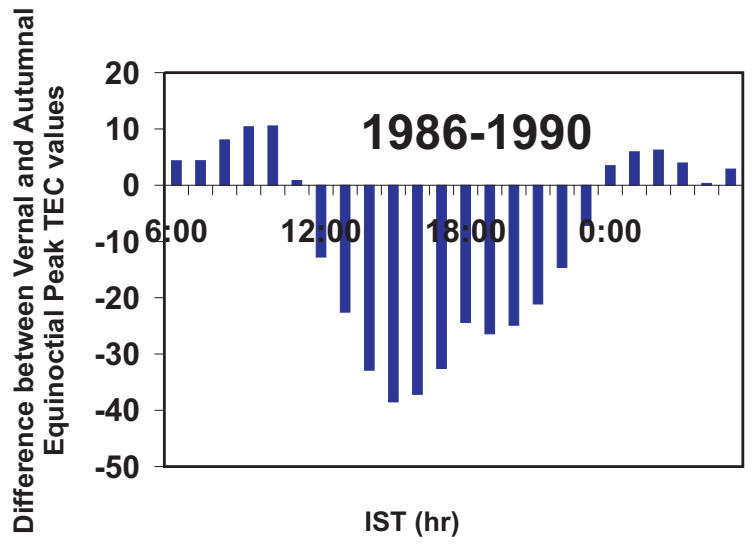

Fig. 7. Difference between peak TEC amplitudes of vernal and autumnal equinoxes vs. local times (IST (h)), obtained from a seasonal plot (Fig. 6). It shows local time dependent features of seasonal peak amplitudes.

than in summer may account, in principle, for the winter anomaly. Further, the overall heat input is greater in the Southern Hemisphere (Barlier et al., 1974) and it provides a net northward wind across the equator. At low latitudes, the trans-equatorial wind gives an increased flow of ionization from the daytime equatorial fountain (Anderson and Roble, 1981). A summer-to-winter trans-equatorial wind produces an increased peak density, and hence the larger winter values (Titheridge and Buonsantu, 1983; Rishbeth et al., 2000). It was reported by model calculation (Richard and Torr, 1986) that the vibrational excitation of $\mathrm{N}_{2}$ becomes an important factor for seasonal anomaly. The high electron temperature possible at solar maximum may enhance the vibrational excitation of $\mathrm{N}_{2}$ sufficiently to reduce the calculated $\mathrm{O}^{+}$density by a factor of 2 in summer while not greatly affecting the winter density. At solar minimum elevated vibrational excitation of $\mathrm{N}_{2}$ causes only a $30 \%$ increase in the effective $\mathrm{N}_{2}$ sink of $\mathrm{O}^{+}$. From October to April, throughout the day, the neutral wind blows predominantly northward, thus increasing the TEC values. The density of atomic oxygen increases near the equinoxes, reducing the diffusive loss and increasing the ionization/TEC (Titheridge and Buonsantu, 1983). Further suggestion was made that not only composition changes but the equatorial fountain effect also modifies the ionization profile near the latitude of $20^{\circ} \mathrm{N}$. An important feature of the seasonal variation in TEC is the local time dependence of the asymmetrical semiannual peak amplitudes. This equinoctial asymmetry was suggested to be related to the changes in the global atmospheric circulation at the equinox (Essex, 1977). During both the high and low solar activity periods, an altitude dependence of equinoctial asymmetry in electron density $(\mathrm{Ne})$ was reported by Balan et al. $(1997,1998)$ and Kawamura et al. (2002) using MU radar observations at a mid-latitude station. It was suggested that the asymmetry in the production-dominated bottom side ionosphere arises 


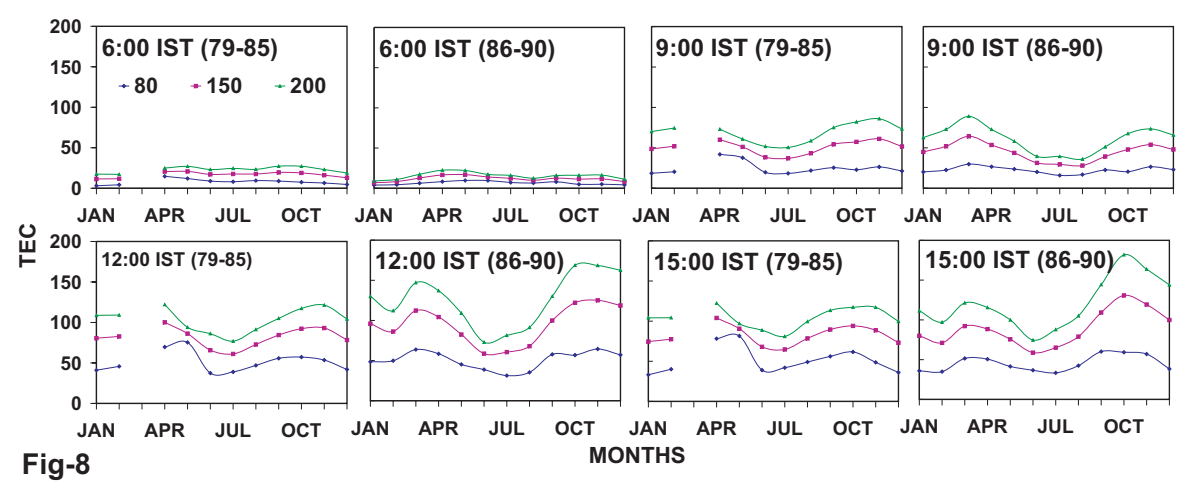

Fig. 8. Seasonal variation of TEC, normalized with respect to F10.7=80, 150, 200 unit. The higher the solar flux values - the higher the ambient ionization level.

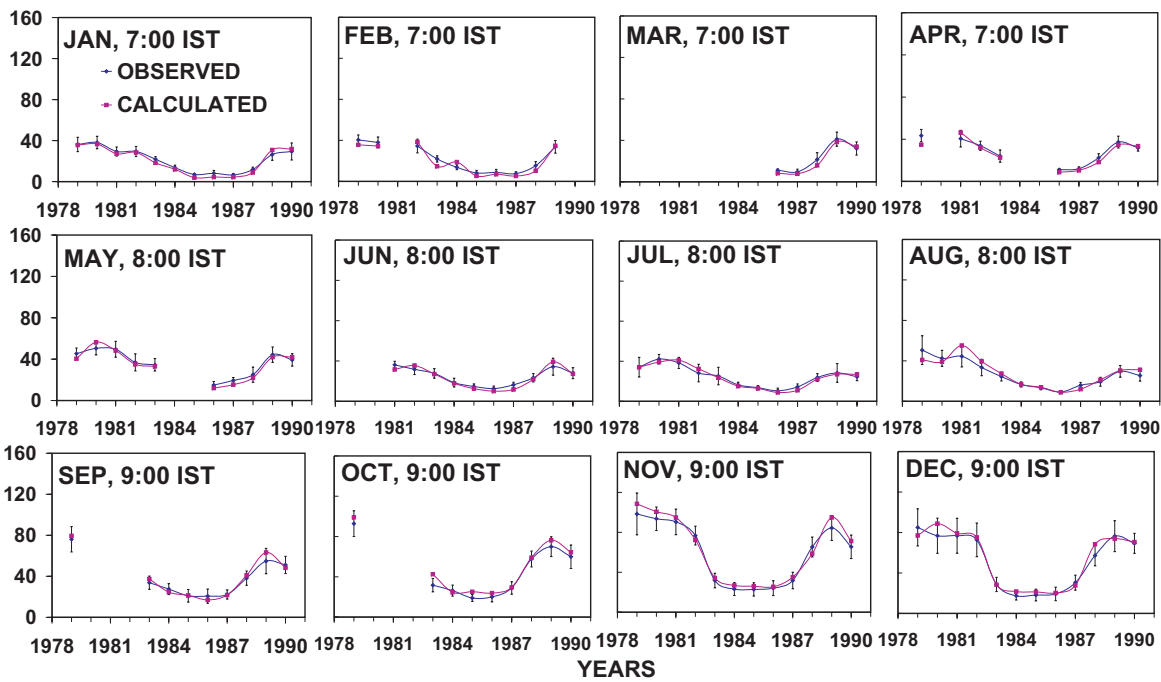

Fig. 9. Monthly plots of calculated (using empirical formula) and observed values of TEC for the period 1979-1990.

mainly from the asymmetry in the thermospheric composition. The asymmetry in the higher altitudes in the ionosphere, where dynamical processes dominate, arises as a result of asymmetries in the local time variation of meridional component of the neutral wind and the perpendicular $\boldsymbol{E} \times \boldsymbol{B}$ plasma drift velocities. The northward meridional wind during the daytime was reported to be higher in the September equinox than in the March equinox while the vertical plasma drift velocity during the daytime of the March equinox was found to be larger compared to the September equinox. The asymmetries in wind velocity are conducive to the development of equinoctial asymmetry in $\mathrm{Ne}$, with higher values in the March equinox than at the September equinox. TEC, being a height integrated parameter and weighted mostly by topside F-region ionization, should exhibit an asymmetry similar to that in $\mathrm{Ne}$ in the topside.

When TEC is normalized with respect to different solar flux values (F10.7=80, 150, 200 unit) and the correspond- ing seasonal variations are considered, a prominent solar flux dependent feature is reflected in the overall TEC behavior. With high solar flux values two maxima in March/April and September/October/November and one minimum in summer characterize the seasonal variation (Fig. 8). For low solar flux one peak disappears at the evening hours. The trend is similar to that observed by Huang and Cheng (1995) using TEC data from East Asian sector. The seasonal amplitude depends on solar flux, and an increase in the general level of ionization with solar flux is evident. Moreover, for the same ratio of solar flux increase, corresponding ratios of seasonal peak amplitudes of TEC are found to exhibit a local time effect. With the solar flux ratio remaining constant, two maxima, one around 08:00 $\mathrm{h}$ IST and the other around midnight hours, are observed in the ratio of the corresponding equinoctial TEC peak values. Thus, not only solar radiation but also other factors, such as neutral winds, tides and waves, magnetic activity contribute to seasonal variability. When a 


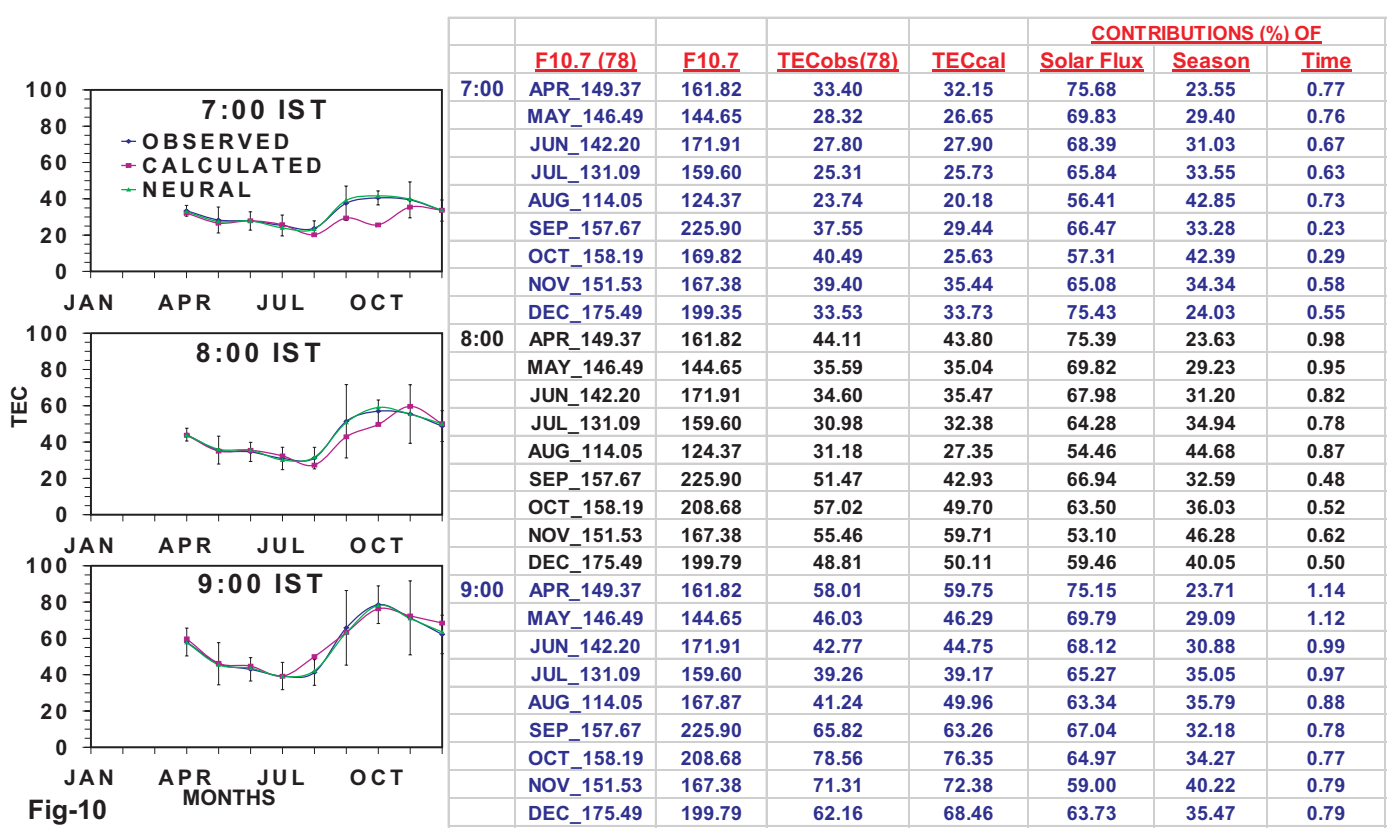

Fig. 10. Monthly plots of TEC values obtained from observations, empirical formula and neural network at the early morning hours of the year 1978 .

polynomial of the sixth degree is fitted to the seasonal variation a good correlation is observed with a high level of significance.

A further normalization of TEC on the seasonal basis yields the variation of TEC with local time. The diurnal minimum is generally observed around 04:00-05:00 h IST, with maximum at 13:00-14:00 $\mathrm{h}$ IST. The nature of the diurnal variation is found to be the same for both solar epochs. The prominent signatures of the secondary enhancement are also observed at the local pre midnight sector of the equinoctial months. A sixth order polynomial fitted to the temporal variation shows a good correlation $\left(R^{2}\right.$ values about 0.99$)$ with a high level of significance.

\section{Development of an empirical formula}

Considering the solar flux, seasonal and local time variations of TEC an empirical formula has been developed for the time interval 07:00-09:00 $\mathrm{h}$ IST. This may give an indication of the solar control of ionization in the morning sector when the transport of ionization by the electrodynamic fountain effect is not so important around the present location. The formula, empirically developed, may be written as

TECcal $=\frac{(m+12)}{(m+6)} \frac{(\mathrm{F} 10.7-1)}{(\mathrm{F} 10.7+200)}\left[\right.$ S.F. $\left.+m\left(\frac{\text { Sea }}{12}\right)+t\left(\frac{\text { Temp }}{24}\right)\right]$
$m=\quad$ month,
$t=\quad$ local time,
F10.7 = value of $10.7 \mathrm{~cm}$ solar flux,
S.F. $=\quad$ contribution of solar flux obtained from TEC vs. solar flux plot,
Sea $=\quad$ seasonal contribution obtained from solar flux normalized TEC plot,
$\mathrm{Temp}=$ local time contribution obtained from temporal plot.

It may be noted that for the present analysis TEC data for the period 1979-1990 have been considered. Results of the calculated values of TEC along with original values are plotted in Fig. 9. All the calculated values fall within the $1 \sigma$ range of the observed values. A further validation of the estimated values has been made using available TEC data for the year 1978 (Fig. 10). Here calculated values also agree well with the observed TEC values except for the months of September and October when deviations are observed to be $15-30 \%$ from experimental values. The side table gives a quantitative estimate of the solar influence on ionization compared to the seasonal and local time contributions. The first column represents the month and monthly mean values of solar flux. The second column represents the matching values of the solar flux in the appropriate solar epoch. The contribution of solar flux is obviously large at the early morning hours. Using the neural network, TEC values for the year 1978 have also been calculated and the corresponding results are plotted in the same figure (Fig. 10). It may thus further validate the empirical formula.

where 


\section{Conclusions}

An intensive study of TEC in association with solar flux over an extended period (1978-1990), from a location near the crest of the equatorial anomaly, reveals a good correspondence between the two when both are considered on a longterm basis. Day-to-day variability of TEC does not follow the solar flux variation trend. This indicates an absence of any short-term relation between TEC and solar radiation. TEC at any location is not a simple function of solar flux alone; neutral wind, tides and waves, transport by the equatorial fountain effect may control its variability. At the early morning hours transport of equatorial ionization by the fountain effect is not so dominant and ionization is mainly controlled by solar radiation. Further, seasonal and local time contributions during this time interval are estimated to be less. The apparent saturation-like effect in the variation of TEC with solar flux, for certain months of the descending phase, needs intensive studies involving various transport parameters and solar EUV radiation. In the long-term variation of TEC with solar flux a prominent hysteresis effect is observed, and may be explained in terms of the cumulative effect of geomagnetic disturbances but the negative hysteresis effect and its phase reversal require further investigations.

Acknowledgements. Authors are greatly indebted to A. DasGupta, University of Calcutta, for supplying original Faraday rotation data, and for useful discussions and valuable suggestions. The work has been carried out with the financial assistance of ISRO under RESPOND Program. A part of this work was presented in IHY-2007 workshop.

Topical Editor M. Pinnock thanks N. Balan and another anonymous referee for their help in evaluating this paper.

\section{References}

Akasofu, S. I.: Relationship between the $\mathrm{AE}$ and $D_{s t}$ indices during geomagnetic storms, J. Geophys. Res., 86, 4820-4822, 1981.

Anderson, D. N. and Roble, R. G.: Neutral wind effects on the equatorial F-region ionosphere, J. Atmos. Terr. Phys., 43, 835843, 1981.

Apostolv, E. M. and Alberca, L. F.: foF2 hysteresis variation and the semiannual geomagnetic wave, J. Atmos. Terr. Phys., 57, 755757, 1995.

Balan, N., Bailey, G. J., and Jayachandran, B.: Ionospheric evidence for a nonlinear relationship between the solar e. u. v. and $10.7 \mathrm{~cm}$ fluxes during an intense solar cycle, Planet Space Sci., 41, 141-145, 1993.

Balan, N. and Bailey, G. J.: Equatorial plasma fountain and its effects: Possibility of an additional layer, J. Geophys. Res., 100, 21 421-21 432, 1995.

Balan, N., Otsuka, Y., and Fukao, S.: New aspects in the annual variation of the ionosphere observed by the MU radar, Geophys. Res. Lett., 24, 2287-2290, 1997.

Balan, N., Otsuka, Y., Bailey, G. J., and Fukao, S.: Equinoctial asymmetries in the ionosphere and thermosphere observed by the MU radar, J. Geophys. Res., 103, 9481-9495, 1998.
Barlier, F., Bauer, P., Jaeck, C., Thuillier, G., and Kockarts, G.: North-south asymmetries in the thermosphere during the last maximum of solar cycle, J. Geophys. Res., 79, 5273-5285, 1974.

Davies, K.: Ionospheric Radio, IEE Electromagnetic Waves Series, Peter Peregnnus Ltd. UK, 31, 137 pp., 1989.

Doherty, P. H., Klobuchar, J. A., and Kunches, J. M.: Eye on the ionosphere: the correlation between solar $10.7 \mathrm{~cm}$ radio flux and ionospheric range delay, GPS Solutions, 3(No.4), 75-79, 2000.

Emmert, J. T., Faivre, M. L., Hernandez, G., Jarvis, M. J., Meriwether, J. W., Niciejewski, R. J., Sipler, D. P., and Tepley, C. A.: Climatologies of nighttime upper thermospheric winds measured by ground-based Fabry-Perot interferometers during geomagnetically quiet conditions: 1. Local time, latitudinal, seasonal, and solar cycle dependence, J. Geophys. Res., 111, A12302, doi:10.1029/2006JA011948, 2006.

Essex, E. A.: Equinoctial variations in the total electron content of the ionosphere at northern and southern hemisphere stations, J. Atmos. Terr. Phys., 39, 645-650, 1977.

Feichter, E. and Leitinger, R.: A 22-Years Cycle in the F layer ionization of the ionosphere, Ann. Geophys., 15, 1015-1027, 1997.

Fejer, B. G. and Scherliess, L.: On the variability of equatorial Fregion vertical plasma drifts, J. Atmos. Sol-Terr. Phys., 63, 893897, 2001.

Garriott, O. K. and Smith III, F. L.: The rate of production of electrons in the ionosphere, Planet. Space Sci., 13, 839-849, 1965.

Golton, E. and Walker, G. O.: Observations of ionospheric electron content across the equatorial anomaly at sunspot minimum, J. Atmos. Terr. Phys., 33, 1-11, 1971.

Gupta, J. K. and Singh, L.: Long term ionospheric electron content variations over Delhi, Ann. Geophysicae, 18, 1635-1644, 2001.

Hanson, W. B. and Moffett, R. J.: Ionization transport effects in the equatorial F region, J. Geophys. Res., 71, 5559-5572, 1966.

Huang, Y. N.: The hysteresis variation of the semi thickness of the F2 layer and its relevant phenomena at Kokubunji, Japan, J. Atmos. Terr. Phys., 25, 638-647, 1963.

Huang, Y. N. and Bor-Shenn, Jeng: A further study on the hysteresis variation of the $\mathrm{F} 2$ layer semi thickness parameter ypF2 at Kokubunji, Japan, J. Atmos. Terr. Phys., 38, 319-323, 1976.

Huang, Y. N. and Cheng, K.: Solar cycle variation of the total electron content around equatorial anomaly crest region in east Asia, J. Atmos. Terr. Phys., 57, 1503-1511, 1995.

Huang, Y. N., Cheng, K., and Chen, S. W.: On the equatorial anomaly of the ionospheric total electron content near the northern anomaly crest, J. Geophys. Res., 94, 13 515-13 525, 1989.

Igi, S., Oliver, W. L., and Ogawa, T.: Solar cycle variations of the thermospheric meridional wind over Japan derived from measurements of $\mathrm{h}_{m} \mathrm{~F}_{2}$, J. Geophys. Res., 104, 22 427-22 431, 1999.

Iyer, K. N. and Rastogi, R. G.: Integrated production and effective loss rates in the ionosphere, Proc. Indian Acad. Sci., 87A (E \& P Sciences-2), 147-153, 1978.

Jayachandran, B., Krishnankutty, T. N., and Gulyaeva, T. L.: Climatology of ionospheric slab thickness, Ann. Geophys., 22, 25-33, 2004 , http://www.ann-geophys.net/22/25/2004/.

Kane, R. P.: Hysteresis and non-linearity between solar EUV and $10.7 \mathrm{~cm}$ fluxes, Ind. J. Radio Space Phys., 34, 161-170, 2005.

Kawamura, S., Balan, N., Otsuka, Y., and Fukao, S.: Annual and semiannual variations of the midlatitude ionosphere under low solar activity, J. Geophys. Res., 107, A81166, 
doi:10.1029/2001JA000267, 2002.

King, J. W., Hawkins, G. L., and Seabrook, C.: The seasonal behavior of the topside ionosphere, J. Atmos. Terr. Phys., 30, 17011706, 1968.

Klobuchar, J. A., Anderson, D. N., and Doherty, P. H.: Model Studies of the latitudinal extent of the equatorial anomaly during equinoctial conditions, Radio Sci., 26, 1025-1047, 1991.

Mahajan, K. K. and Dwivedi, A. K.: Solar EUV flux during sunspot cycles 21, 22 and 23-Correlation with proxy indices and real time prediction, Ind. J. Radio Space Phys., 34, 153-160, 2005.

Mikhailov, A. V. and Marin, D.: An interpretation of the foF2 and $\mathrm{hmF} 2$ long-term trends in the framework of the geomagnetic control concept, Ann. Geophys., 19, 733-748, 2001.

Millward, G. H., Rishbeth, H., Fuller-Rowell, T. J., Aylward, A. D., Quegan, S., and Moffett, R. J.: Ionospheric $\mathrm{F}_{2}$ layer seasonal and semiannual variations, J. Geophys. Res., 101, 5149-5156, 1996.

Prasad, D. S. V. V. D. and Rama Rao, P. V. S.: Day-to-day variability of ionospheric electron content over Waltair, Ind. J. Radio Space Phys., 22, 391-396, 1993.

Raghava Reddi, C., Vaidyanathan, S., and Krishna Murthy, B. V.: Studies on ionospheric electron content at the magnetic equator, Ann. Geophys., 38, 37-49, 1982, http://www.ann-geophys.net/38/37/1982/.

Rao, M. S. V. G. and Rao, R. S.: The hysteresis variation in F2 layer parameters, J. Atmos. Terr. Phys., 31, 1119-1125, 1969.

Rastogi, R. G. and Rajaram, G.: Electrojet effects on the equatorial F-region during magnetically quiet and disturbed days, Indian J. Pure Appl. Phys., 9, 531-536, 1971.

Rastogi, R. G. and Sharma, R. P.: Ionospheric electron content at Ahmedabad (near the crest of equatorial anomaly) by using beacon satellites transmissions during half a solar cycle, Planet. Space Sci., 19, 1505-1517, 1971.
Richard, P. G. and Torr, D. G.: A factor of 2 reduction in theoretical F2 peak electron density due to enhanced vibrational excitation of $\mathrm{N}_{2}$ in summer at solar maximum, J. Geophys. Res., 91, 11331-11336, 1986.

Rishbeth, H., Sedgemore-Schulthess, K. J. F., and Ulich, T.: Semiannual and annual variations in the height of the ionospheric F2peak, Ann. Geophys., 18, 285-299, 2000.

Rush, C. M. and Richmond, A. D.: The relationship between the structure of the equatorial anomaly and strength of the equatorial electrojet, J. Atmos. Terr. Phys., 35, 1171-1180, 1973.

Sethia, G., Rastogi, R. G., Deshpande, M. R., and Chandra, H.: Equatorial electrojet control of the low latitude ionosphere, J. Geomag. Geoelectr., 32, 207-216, 1980.

Smith, P. A. and King, J. W.: Long-term relationship between sunspots, solar faculae and the ionosphere, J. Atmos. Terr. Phys., 43, 1057-1063, 1981.

Titheridge, J. E.: Exospheric temperature and composition from satellite beacon measurements, Planet. Space Sci., 22, 209-222, 1974.

Titheridge, J. E. and Buonsantu, M. J.: Annual variations in the electron content and height of the F layer in the northern and southern hemispheres, related to neutral composition, J. Atmos. Terr. Phys., 45, 683-696, 1983.

Wu, C. C., Fry, C. D., Liu, J. Y., Liou, K., and Tseng, C. L.: Annual TEC variation in the equatorial anomaly region during the solar minimum: September 1996-August 1997, J. Atmos. Sol.-Terr. Phy., 66, 199-207, 2004. 